\title{
Numerical Simulations of Temperature- dependence on Distributed Bragg Reflector (DBR) and Performance Analyses for Proton- Implant/Oxide Confined VCSEL: Comparison with Transmission Matrix, Matrix Calculating Methods and Macleod Model
}

\author{
Tzu-Chiang Chen \\ Chung Cheng Institute of Technology, National Defense University \\ Taiwan, Republic of China
}

\section{Introduction}

This chapter mainly focuses on the simulation for temperature-dependent Distributed Bragg Reflector (DBR) of 850nm vertical cavity surface emitting laser (VCSEL) with Transmission Matrix (TMM), Matrix Calculating Methods (MCM) and Macleod Model and performance for comparison with proton-implant/oxide confined process on VCSEL. Using welldeveloped temperature-dependent DBR-reflectivity solver with Mathcad simulator, we have successfully compared the Macleod Model simulator with theoretical self-developed solution based on the Transmission Matrix (TMM), Matrix Calculating Methods (MCM) and find very good agreement with previous results while accounting for influences of conjugated part of refractive index and graded $\mathrm{Al}$ compositions of DBR materials. Moreover, optoelectronic performance of Proton-Implant/Oxide Confined $850 \mathrm{~nm}$ VCSEL have been demonstrated on this chapter using temperature-dependent power output, voltage/injection current, transverse operating wavelengths, optical spectral characteristics, slope efficiency and transverse optical modes with an approximated Marcatili's method extracted and measurement from systematically measuring experiments. Through adequate and precise LD device design and processes, we have proposed the high performance single-mode proton implanted in contrast to the oxide confined $850 \mathrm{~nm}$ VCSEL. Under nominal temperature-variety and keeping operating temperature of $30^{\circ} \mathrm{C}$, the maximum power output of 10 micro meter aperture proton implanted VCSEL exceeds $5 \mathrm{~mW}$ while injecting current of $10 \mathrm{~mA}$, and the threshold voltage, injecting current, peak-wavelength, differential resistance are $1.8 \mathrm{~V}, 3.2 \mathrm{~mA}, 851 \mathrm{~nm}$ and $36.8 \mathrm{ohm}$, respectively.

\section{Research focuses}

Vertical cavity surface emitting laser has a number of inherent advantages including low divergence of the circular beam, which is emitted from the top surface of the laser diode in 
order to efficiently couple into fiber for communication. One of the most unique characteristic operation of a VCSEL is that it operates in single longitudinal mode due to its natively short effective cavity length. And many researchers also try to achieve high efficiency, high power, single transverse mode operation and insensitive temperature feature in VCSEL for high-speed light-wave communication and higher information capacity of the communication-linking network. By far, the common compound semiconductor material used for fabricating the reflector mirrors of VCSEL is the AlGaAs system because of the large refractive index difference between the lattice matched GaAs and AlAs binaries. J. Talghader et.al. have investigated the thermal dependence of the refractive index of GaAs and AlAs measured using semiconductor multiplayer optical cavities (J. Talghader et.al., 2003). The VCSEL-type passive optical cavities exhibiting substantially different longitudinal optical mode shifts with temperature has been demonstrated. For conventional edge-emitting semiconductor lasers, the far-field and beam characteristics depend on laser structure. However, the detailed study of far-field modes and beam features for VCSEL with different window diameters $(\omega)$ and active-layer apertures (s) as function of injected current has been proposed at a certain temperature (Iga, K. et.al., 1984). In our study, the temperature-dependent reflectivity spectra of linear graded Al-composition DBR in $850 \mathrm{~nm}$-VCSEL were simulated and analyzed using two-kinds of transfer matrix methods, which compared with the results from the multi-layer films evolution software of essential Macleod. To our knowledge, little work has yet investigated the thermal effect on spatial distributions of far-fields patterns. So, the influences of injected current and temperature-varying have been displayed in this work.

\section{Theory and experimental setups}

\subsection{Description of VCSEL structure}

The VCSEL studied are $1 \lambda$ cavity length, GaAs quantum well (QW)-based structure with 15 $\mu \mathrm{m}$-circular selectively oxided cavity apertures for current confinement. As seen in Fig.1, the DBR mirrors were formed with alternating layers of top graded mirrors of 20 pairs of $\mathrm{Al}_{\mathrm{x}} \mathrm{Ga}_{1-\mathrm{x}} \mathrm{As} / \mathrm{Al}_{\mathrm{y}} \mathrm{Ga}_{1-\mathrm{y}} \mathrm{As}(\mathrm{x}=0 \sim 0.9, \mathrm{y}=0 \sim 0.12$ ) quarter-wave stacks and a bottom mirror of 34 pairs of $\mathrm{Al}_{\mathrm{y}} \mathrm{Ga}_{1-\mathrm{y}} \mathrm{As} / \mathrm{Al}_{\mathrm{x}} \mathrm{Ga}_{1-\mathrm{x}} \mathrm{As}$ quarter-wave stacks. The graded $\mathrm{Al}$ composition in DBR mirrors is to built electric field uniformly in the VCSEL structure which avoid sharp energy discontinuity between DBR and active region. Three periods of quantum wells are sandwiched with double DBRs and centered in active region; lasing occurs in the $850 \mathrm{~nm}$

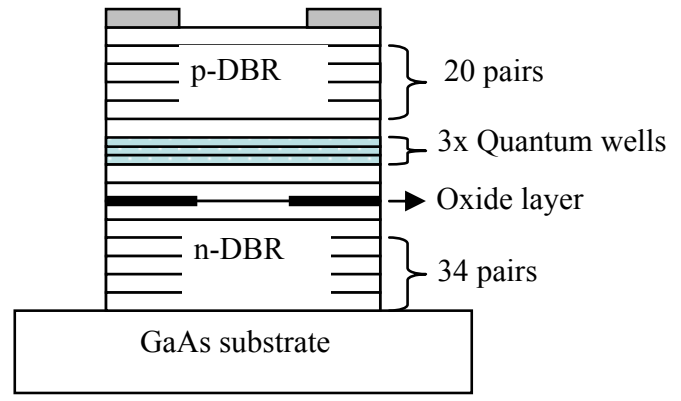

Fig. 1. Structure of the selectively oxidized VCSEL with circular aperture of $10 \mu \mathrm{m}$ in diameter and with active region of quantum well as the gain medium 
range for the fundamental mode. The excess two thin layers of $\mathrm{Al}_{0.98} \mathrm{Ga}_{0.02} \mathrm{As}$ are oxidized to efficiently form a circular aperture. The top and bottom DBR mirrors were doped moderately for decreasing the series resistance of VCSEL.

\subsection{Calculation of refractive index of $\mathrm{Al}_{\mathrm{x}} \mathrm{Ga}_{1-\mathrm{x}} \mathrm{As}$}

We use a semi-empirical method for calculating the room temperature refractive index of $\mathrm{Al}_{\mathrm{x}} \mathrm{Ga}_{1-\mathrm{x}} \mathrm{As}$ at energies below the direct band edge and this quantity is important in the design of GaAs heterostructure lasers. M. A. Afromowitz has used the interpolation scheme and compare the results of the calculation of refractive index for the $\mathrm{Al}_{x} \mathrm{Ga}_{1-\mathrm{x}} \mathrm{As}$ with experimental data (M. A. Afromowitz, 1974). From this model, these equation of $n(x, \lambda)$ reproduces as yielding,

$$
n(x, \lambda)=\sqrt{\left[\frac{E_{d}(x)}{E_{o}(x)}+\frac{E_{d}(x) \times E_{p}^{2}(\lambda)}{E_{o}^{3}(x)}+\frac{E_{d}(x) \times E_{p}^{4}(\lambda)}{2 \times E_{o}^{3}(x) \times\left(E_{o}^{2}(x)-E_{\Gamma}^{2}(x)\right)} \times \ln \left(\frac{2 \times E_{o}^{2}(x)-E_{\Gamma}^{2}(x)-E_{p}^{2}(\lambda)}{E_{\Gamma}^{2}(x)-E_{p}^{2}(\lambda)}\right)\right]+1}
$$

where $\mathrm{n}$ denotes the refractive of $\mathrm{Al}_{\mathrm{x}} \mathrm{Ga}_{1-\mathrm{x}} \mathrm{As}, \mathrm{x}: \mathrm{Al}$ composition, $\lambda$ : optical light wavelength, Ep: incident optical energy, $\mathrm{E}_{0}$ : effective oscillated energy, $\mathrm{E}_{\mathrm{d}}$ : dispersion energy, and $\mathrm{E}_{\Gamma}$ : band gap energy. The equations for $\mathrm{E}_{0}, \mathrm{E}_{\mathrm{d}}$, and $\mathrm{E}_{\Gamma}$ as the function of alloy composition yield

$$
\begin{gathered}
E_{p}(\lambda)=\frac{1.239852066 \times 10^{3}}{\lambda} \\
E_{o}(x)=3.65+0.871 \times x+0.179 \times x^{2} \\
E_{d}(x)=36.1-2.45 \times x \\
E_{\Gamma}(x)=1.424+1.266 \times x+0.26 \times x^{2}
\end{gathered}
$$

In this section, using two kinds of described methods for transfer matrix method simulate DBR mirrors (C. Chen, 2002). The detailed deduction of the models as follows:

\subsection{Transmission matrix method, TMM (Furman, Sh.et.al., 2002)}

Consider the optical waves are propagated along with z-direction as shown in Fig. 2 And the electric fields display as the next two equations:

$$
\begin{gathered}
A_{j}\left(z_{2}\right)=e^{-j \beta_{i}\left(z_{2}-z_{1}\right)} A_{i}\left(z_{2}\right) \\
B_{j}\left(z_{2}\right)=e^{j \beta_{i}\left(z_{2-} z_{1}\right)} B_{i}\left(z_{2}\right) \\
\beta_{i}=k_{o} n_{i}=k_{o}\left(n_{i, r e}+n_{i, i m}\right) k_{o}=\frac{2 \pi}{\lambda}
\end{gathered}
$$

where $\beta_{i}$ is propagation constant, $k_{o}$ : wave number, $n_{i}$ : complex refraction index, $n_{i, r e}$ : refraction index, $n_{i, i m}$ : extinction coefficient 
For the purpose of convenience, the equations (6) and (7) can be achieved as matrix type :

$$
\left[\begin{array}{l}
A_{j}\left(z_{2}\right) \\
B_{j}\left(z_{2}\right)
\end{array}\right]=\left[\begin{array}{cc}
e^{-j \beta_{i} L} & 0 \\
0 & e^{j \beta_{i} L}
\end{array}\right]\left[\begin{array}{l}
A_{i}\left(z_{1}\right) \\
A_{i}\left(z_{1}\right)
\end{array}\right]=P_{i}\left[\begin{array}{l}
A_{i}\left(z_{1}\right) \\
A_{i}\left(z_{2}\right)
\end{array}\right]
$$

where $P_{i}$ is propagation matrix, $L=Z_{2}-Z_{1}$,

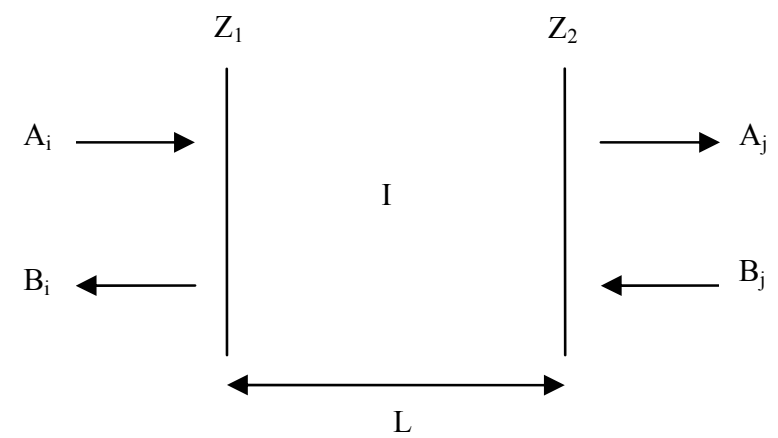

Fig. 2. Schematic diagram of wave propagation in region I

The optical waves are transmitted through the different interface regions as plotted in Fig.3, using the below boundary conditions:

$$
\begin{gathered}
A_{j}+B_{j}=A_{i}+B_{i} \\
-n_{j} A_{j}+n_{j} B_{j}=-n_{i} A_{i}+n_{i}+B_{i}
\end{gathered}
$$

then let equation (10) and (11) exhibit as 2-dimensional matrix type,

$$
\left[\begin{array}{l}
A_{j} \\
B_{j}
\end{array}\right]=\left[\begin{array}{cc}
\frac{n_{j}+n_{i}}{2 n_{j}} & \frac{n_{j}-n_{i}}{2 n_{j}} \\
\frac{n_{j}-n_{i}}{2 n_{j}} & \frac{n_{j}+n_{i}}{2 n_{j}}
\end{array}\right]\left[\begin{array}{c}
A_{i} \\
B_{i}
\end{array}\right]=T_{j, i}\left[\begin{array}{c}
A_{i} \\
B_{i}
\end{array}\right]
$$

in where $T_{j, i}$ is propagation between matrix medium $\mathrm{i}$ and medium $\mathrm{j}$.

$\mathrm{n}_{\mathrm{i}}$

$\mathrm{n}_{\mathrm{j}}$

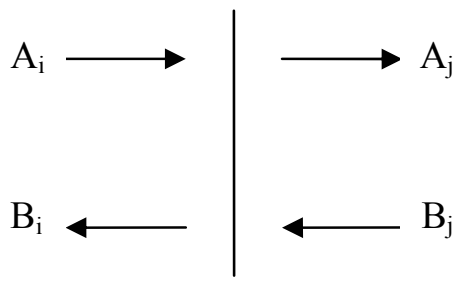

Fig. 3. Schematic diagram of wave propagation in interface between $n_{i}$ and $n_{j}$ 
Now, the structure with multi-layer stacks is displayed in Fig. 4, then the scheme of wave propagation can be written with propagation matrix form,

$$
\begin{gathered}
{\left[\begin{array}{l}
A_{2} \\
B_{2}
\end{array}\right]=T_{P}\left[\begin{array}{l}
A_{1} \\
B_{1}
\end{array}\right]} \\
T_{P}=T_{1,2} P_{2} T_{2,1} P_{1}=\left[\begin{array}{ll}
t_{11} & t_{12} \\
t_{21} & t_{22}
\end{array}\right]
\end{gathered}
$$

Assume $\mathrm{A} 2=0$, the reflective coefficient can be written as:

$$
R_{1}=\frac{A_{1}}{B_{1}}=-\frac{t_{12}}{t_{11}}
$$

then the reflective ratio is shown as

$$
R=\left|R_{1}\right|^{2}
$$

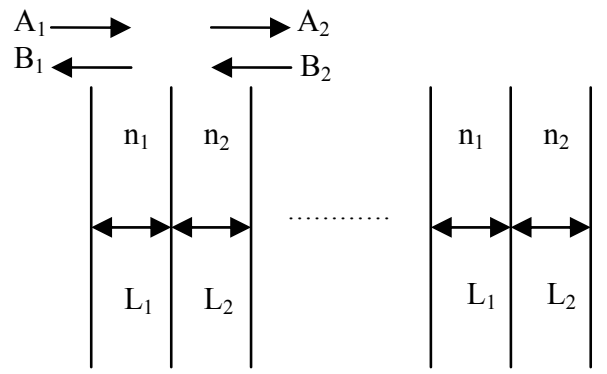

Fig. 4. The multiplayer structure consists of $n_{1}$ and $n_{2}$ mediums

\subsection{Matrix calculating method, MCM (Furman, Sh.et.al., 2002)}

Consider the multiplayer structure as plotted in Fig. 5, the electric field $u(z)$ in layer $\mathrm{j}$ and magnetic field $\mathrm{v}(\mathrm{z})$ are located in contiguous interface. While applying the boundary conditions of transverse electric field, the overall transfer matrix from the first to the $M$ layer can be exhibited in the below matrix:

$$
\left(\begin{array}{l}
u \\
v
\end{array}\right)_{z=z_{j}}=\left(\begin{array}{cc}
\cos \varphi_{j} & \left(i / q_{j}\right) \sin \varphi_{j} \\
i q_{j} \sin \varphi_{j} & \cos \varphi_{j}
\end{array}\right)\left(\begin{array}{l}
u \\
v
\end{array}\right)_{z=z_{j}-1}
$$

where $\varphi_{j}=k n_{j} d_{j}, k=\frac{2 \pi}{\lambda}, d_{j}=z_{j}-z_{j-1}, q_{j}=n_{j}$, let

$$
M_{j}=\left(\begin{array}{cc}
\cos \varphi_{j} & \left(i / q_{j}\right) \sin \varphi_{j} \\
i q_{j} \sin \varphi_{j} & \cos \varphi_{j}
\end{array}\right)
$$


For a series of multi-layer structure, the overall transfer is the product of individual transfer, i.e.,

$$
\begin{gathered}
\left(\begin{array}{l}
u \\
v
\end{array}\right)_{z=z_{a}}=M_{m} M_{m-1} \ldots M_{1}\left(\begin{array}{l}
u \\
v
\end{array}\right)_{z=0} \\
M=M_{m} M_{m-1} \ldots M_{1}=\left(\begin{array}{ll}
m_{11} & m_{12} \\
m_{21} & m_{22}
\end{array}\right)
\end{gathered}
$$

According to overall transfer matrix, the reflective coefficient can be written as:

$$
r=\frac{n_{a} m_{11}-n_{s} m_{22}+n_{a} n_{s} m_{12}-m_{21}}{n_{a} m_{11}+n_{s} m_{22}+n_{a} n_{s} m_{12}+m_{21}}
$$

so, the reflective ratio is described as

$$
R=|r|^{2}
$$

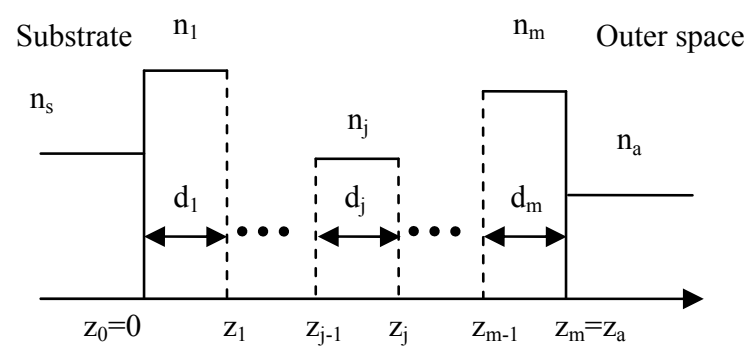

Fig. 5. The schematic diagram of multilayers consisting of substrate and outer space

For further verifying the precision of reflectivity spectra using TMM and MCM method, the multi-layer films evolution software of essential Macleod is utilized to simulate for the same 850nm-VCSEL structure which includes the database built-up refractive index with respect to linearly graded $\mathrm{Al}$ composition from equation (1) to (5). The schematic diagrams of unit period in top and bottom DBR mirrors are shown as Fig. 6(a) and (b), respectively. The unit period of bottom DBR mirror consisting of 4 layers of AlxGa1-xAs(x: 0.12 $\rightarrow 0.9), \mathrm{Al}_{0.9} \mathrm{Ga}_{0.1} \mathrm{As}$, $\mathrm{Al}_{\mathrm{x}} \mathrm{Ga}_{1-\mathrm{x}} \mathrm{As}(\mathrm{x}: 0.9 \rightarrow 0.12)$ and $\mathrm{Al}_{0.12} \mathrm{Ga}_{0.88} \mathrm{As}$ is quasi-symmetric to top one for $\mathrm{Al}_{\mathrm{x}} \mathrm{Ga}_{1-\mathrm{x}} \mathrm{As}(\mathrm{x}$ : $0.9 \rightarrow 0.12), \mathrm{Al}_{0.12} \mathrm{Ga}_{0.88} \mathrm{As}, \mathrm{Al}_{\mathrm{x}} \mathrm{Ga}_{1-\mathrm{x}} \mathrm{As}(\mathrm{x}: 0.12 \rightarrow 0.9)$ and $\mathrm{Al}_{0.9} \mathrm{Ga}_{0.1} \mathrm{As}$. However top and bottom DBR mirrors have 20 and 34 periods, respectively from theoretical calculations.

From simulated results as shown in Fig. 7 and 8, it is notable that the reflectivity spectra achieved from TMM and MCM method are well agreed with the ones from using Macleod software at room temperature. The maximum reflectivity of top and bottom DBR mirrors are $>96.4 \%$ and $99.98 \%$. The peak wavelengths are located in $840 \mathrm{~nm}$. It can overall satisfy the specification of high DBR performance. 


\begin{tabular}{|c|}
\hline $\mathrm{Al}_{0.9} \mathrm{Ga}_{0.1} \mathrm{As}$ \\
\hline $\mathrm{Al}_{\mathrm{x}} \mathrm{Ga}_{1-\mathrm{x}} \mathrm{As}(\mathrm{x}: 0.12 \rightarrow 0.9)$ \\
\hline $\mathrm{Al}_{0.12} \mathrm{Ga}_{0.88} \mathrm{As}$ \\
\hline $\mathrm{Al}_{\mathrm{x}} \mathrm{Ga}_{1-\mathrm{x}} \mathrm{As}(\mathrm{x}: 0.9 \rightarrow 0.12)$ \\
\hline $\mathrm{GaAs}$ substrate \\
\hline
\end{tabular}

\begin{tabular}{|c|}
\hline $\mathrm{Al}_{0.12} \mathrm{Ga}_{0.88} \mathrm{As}$ \\
\hline $\mathrm{Al}_{\mathrm{x}} \mathrm{Ga}_{1-\mathrm{x}} \mathrm{As}(\mathrm{x}: 0.9 \rightarrow 0.12)$ \\
\hline $\mathrm{Al}_{0.9} \mathrm{Ga}_{0.1} \mathrm{As}$ \\
\hline $\mathrm{Al}_{\mathrm{x}} \mathrm{Ga}_{1-\mathrm{x}} \mathrm{As}(\mathrm{x}: 0.12 \rightarrow 0.9)$ \\
\hline $\mathrm{GaAs}$ substrate \\
\hline
\end{tabular}

Fig. 6. Unit periods of (a) top and (b) bottom DBR mirror

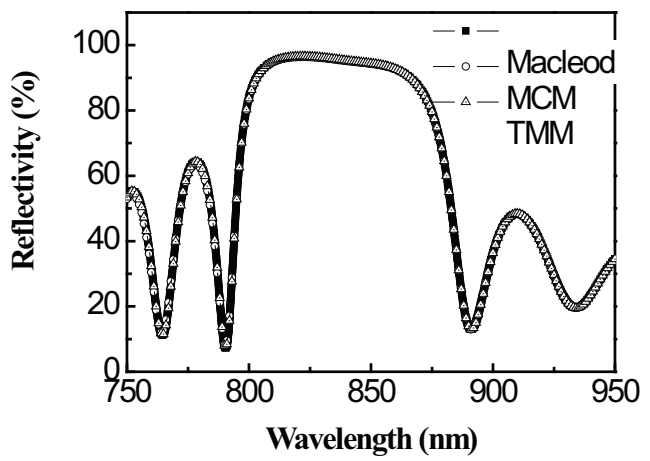

Fig. 7. The spectra of top-DBR mirror

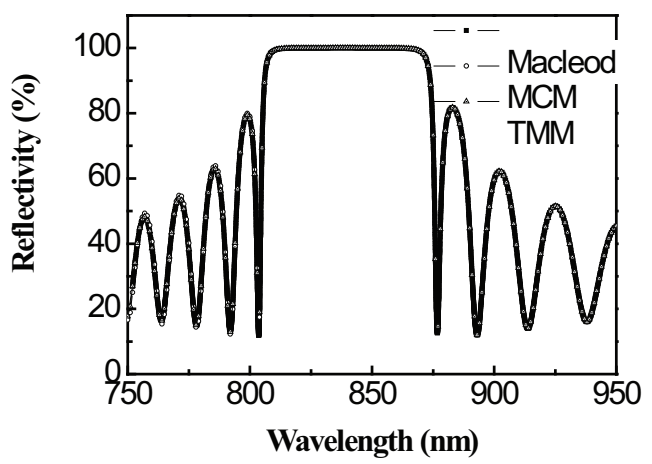

Fig. 8. The spectra of bottom-DBR mirror

Next, considering the temperature-dependent refractivity of DBR mirrors, it is due to the changes of refractive indexes in linearly graded $\mathrm{Al}_{x} \mathrm{Ga} 1-x \mathrm{As}$ and GaAs. (J. Talghader et.al., 2003) as follows:

$$
(d n / d T)_{G a A s}=(2.67 \pm 0.07) \times 10^{-4} /{ }^{\circ} \mathrm{C},
$$




$$
(d n / d T)_{A l A s}=(1.43 \pm 0.07) \times 10^{-4} /{ }^{\circ} \mathrm{C}
$$

Estimate the temperature influences on reflectivity spectra from adding the equation (22) and (23) into the previous TMM, MCM method and material database in Macleod software. From Fig. 9 and 10, it is only $0.5 \AA /{ }^{\circ} \mathrm{C}$ of spectra red-shift in DBR mirrors from 30 to $80^{\circ} \mathrm{C}$, which are comparable with the proposed results from J. L. Shen et.al. (S. Chuang, 1995)

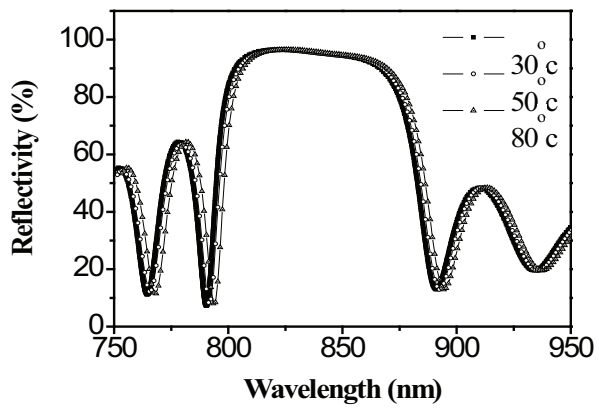

Fig. 9. The temperature dependent spectra of top-DBR mirror

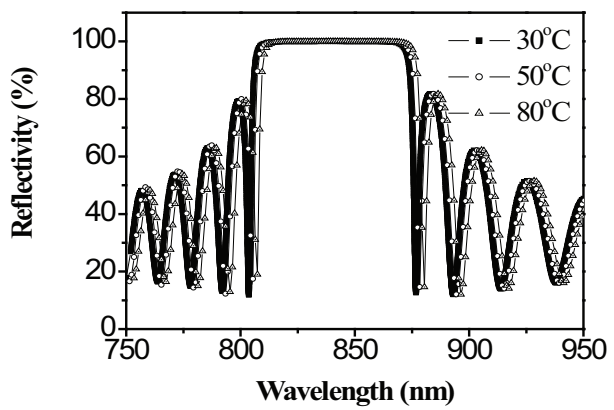

Fig. 10. The temperature dependent spectra of top-DBR mirror

\section{Theory of optical dielectric slab waveguides (S. Chuang, 1995)}

The dielectric waveguide theory is very useful studying heterojunction semiconductor lasers and the far-field patterns of VCSEL can be explained with the optical waveguide theory in our experiments. At first, let us consider a slab waveguide as shown in Fig. 11, where the width $\mathrm{w}>>$ thickness $d$, and the field dependence on $\mathrm{y}$ is negligible, i.e., $\partial / \partial y \equiv 0$. From the wave equation

$$
\left(\nabla^{2}+\omega^{2} \mu \varepsilon\right) E=0
$$

We shall find the solutions for the fields everywhere. We assume that the waveguide is symmetric, that is, the permittivity and the permeability are $\varepsilon$ and $\mu$, respectively, for 
$|\mathrm{x}| \geqq \mathrm{d} / 2$, and $\varepsilon 1$ and $\mu 1$ for $|\mathrm{x}|<\mathrm{d} / 2$. The origin has been chosen to be at the center of the guide, since the waveguide is symmetric; therefore, we have even-mode and odd-mode solutions. Wee separate the solutions of the fields into two classes: TE polarization and TM polarization. Here, a waveguide mode or a normal mode is defined as the wave solution to Maxwell's equations with all of the boundary conditions satisfied; the transverse spatial profile and its polarization remain unchanged while propagating down the waveguide.

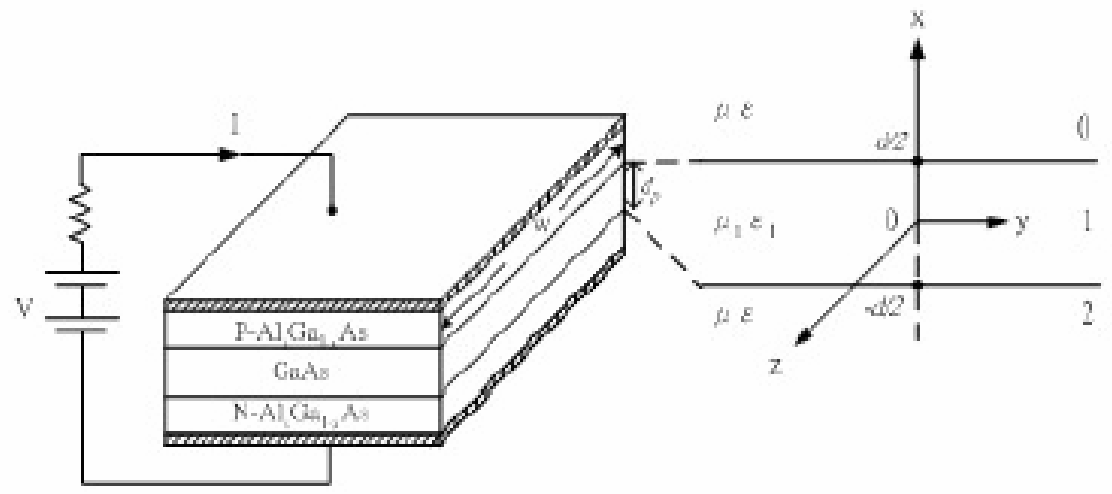

Fig. 11. A simplified heterojection diode structure for waveguide analysis

\section{Experimental setups for L-I-V and far-field patterns}

The capturing the electronic and optical output characteristics of $850 \mathrm{~nm}$ VCSEL were achieved with setup diagram as shown in Fig. 12. At first, the device is mounted on 3-D axis holder consisting of the copper plate hybridized with TE cooler and temperature sensor assembly controlled by temperature controller. The temperature range can be tuned from 30 to $100{ }^{\circ} \mathrm{C}$. Then the electro-probe is linked between R6243 LD Driver (S. T. Su, et.al., 2006) and the device. The near-IR detector is collected with Q8221 Optical Power Meter

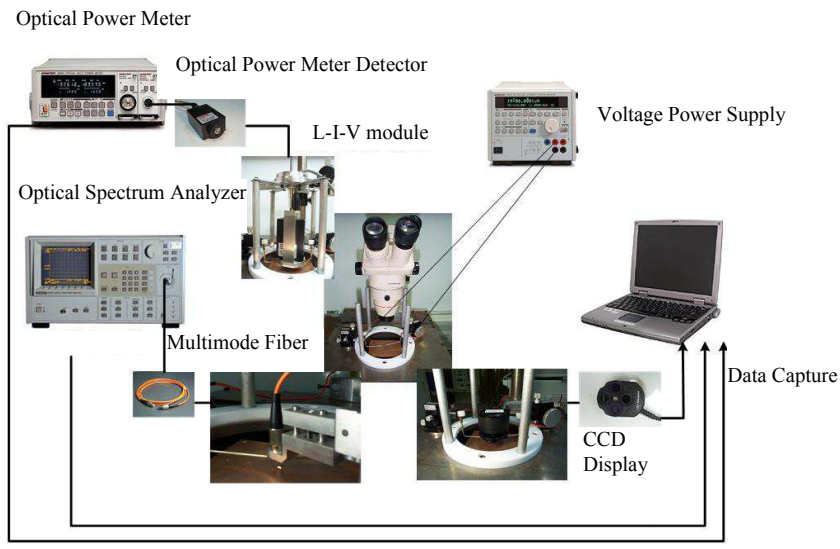

Fig. 12. The electronic and optical measurements consisting of L-I-V, spectra and far-field pattern 
(Advantest Corp., 2002) for L-I measurement or Advantest Q8383 Optic Spectrum System (Advantest Corp., 1994) for LD spectra. All the equipments are controlled by the computer through the NI-GPIB interfaces. The Newport Beam Profile Acquisition module is separated from the above equipments excluding the temperature varying system for far-field pattern measurement.

In addition, measures the characteristic which temperature-dependent. Install the device which temperature changing on $\mathrm{n} 3$-D axis holder consisting of the copper plate hybridized. Designed temperature-dependent measuring system is demonstrated in Fig. 13. Variable temperature unit include thermoelectric cooler, temperature controller, heat sink and temperature Sensor. The temperature controller controls the power that the cooler device outputs. Then reach temperature the temperature controller from temperature sensing device that purpose to achieve temperature control.

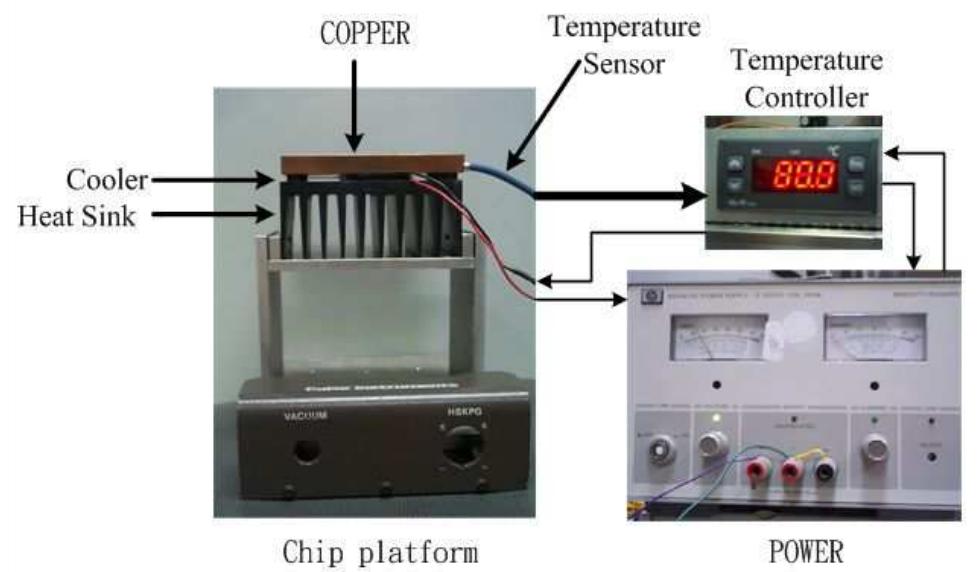

Fig. 13. Variable temperature measuring system

\section{Results and discussions}

\subsection{Oxide confined $850 \mathrm{~nm}$ VCSEL}

Using best empirical and selectively oxidized parameters of device process, the temperature-dependent I-V measurement of the optimized VCSEL sample are shown in Fig.14. From 30 to $80^{\circ} \mathrm{C}$ of I-V measurement, temperature is the higher and the higher slope of IV-curve is presented. While showing the environment temperature rises, energy gap and energy barrier reduce of material. So, diffused current is easy to cross energy gap of surface. On the other hand, the surface defect of junction will be reduced to catch electrons with improvement of temperature, too. The differential resistances of the optimized VCSEL sample are shown in Fig. 15. From 30 to $80{ }^{\circ} \mathrm{C}$ and oxidized times of $70 \mathrm{~min}$, the averagely differential resistance of Oxide confined $850 \mathrm{~nm}$ VCSEL is $25 \Omega$.

The temperature-dependent spectra of the optimized VCSEL sample are shown in Fig. 16. From 30 to $80{ }^{\circ} \mathrm{C}$ and under the driving current of $30 \mathrm{~mA}$ and oxidized times of $70 \mathrm{~min}$, the 


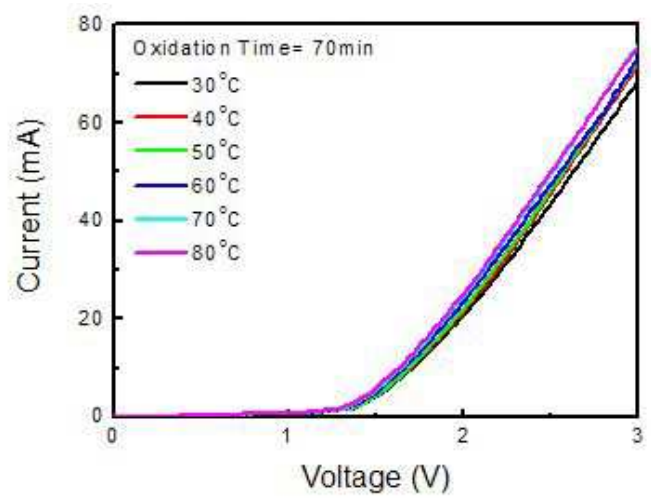

Fig. 14. I-V curve of oxide confined 850nm VCSEL devices

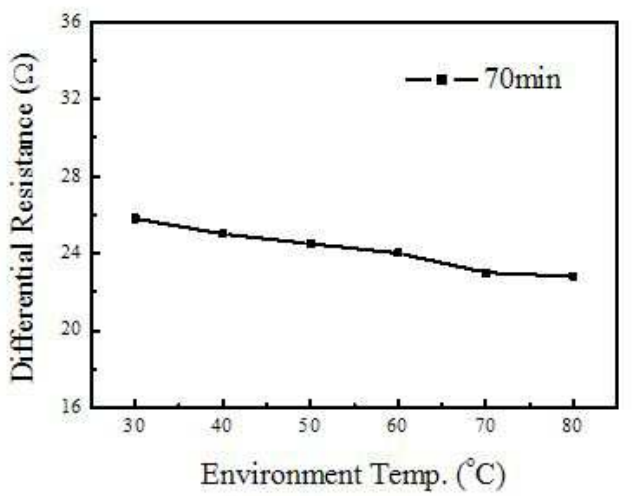

Fig. 15. The temperature-dependent Differential Resistance of Oxide confined $850 \mathrm{~nm}$ VCSEL

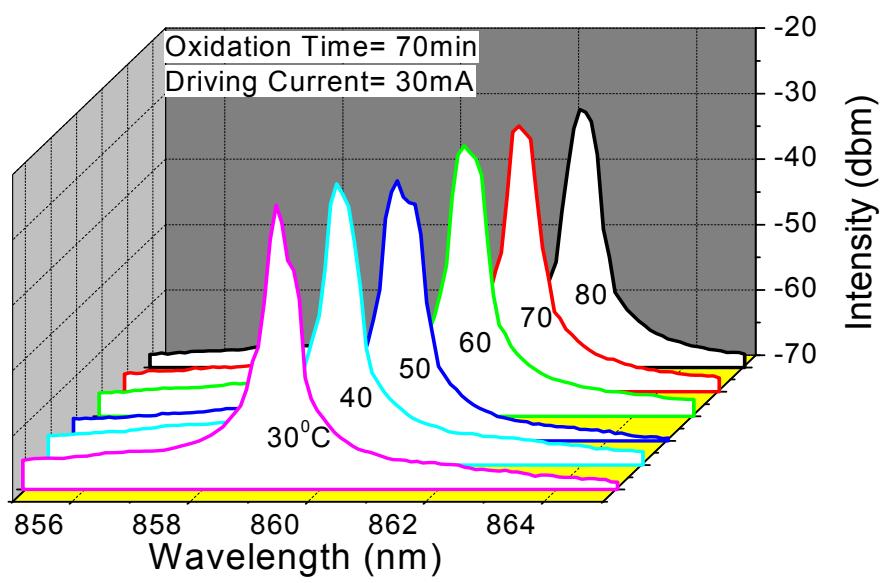

Fig. 16. The temperature-dependent spectra of Oxide confined $850 \mathrm{~nm}$ VCSEL 
spectra exhibit the quiasi-single transverse modes successfully excluding the $50^{\circ} \mathrm{C}$ spectrum due to mode hopping. The shifts of FWHM and peak-wavelength red-shift are $0.71 \pm 0.05$ and $0.06 \mathrm{~nm} /{ }^{\circ} \mathrm{C}$, respectively. In the analysis on far-field patterns (Advantest Corp., 1993), $30^{\circ} \mathrm{C}$ laser beam profiles are shown in Fig. 17 after selectively oxidized times of $60 \mathrm{~min}$. From the diagram, it is clear to note that the $\mathrm{HE}_{10}$ or $\mathrm{EH}_{10}$ lasing modes occur suddenly from spontaneous mode once the injected currents increase to $24 \mathrm{~mA}$. While the injected current increases continuously to $26 \mathrm{~mA}$, the transverse modes are transited to $\mathrm{HE}_{11}$. Many modes happen when the injected current is higher than $27 \mathrm{~mA}$.
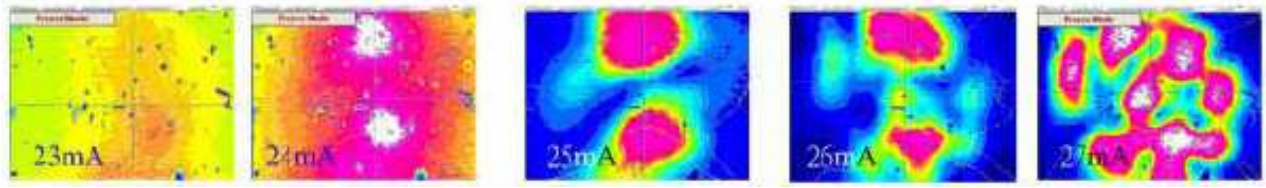

Fig. 17. The far-field pattern of $850 \mathrm{~nm}$ VCSEL as function of injected currents, oxidized times of $60 \mathrm{~min}$

Similarly, $30^{\circ} \mathrm{C}$ laser beam profiles after selectively oxidized times of $70 \mathrm{~min}$ are shown in Fig. 18. From the profiles, it is found that the $\mathrm{HE}_{00}$ fundamental lasing mode occurs suddenly from spontaneous mode once the injected currents increase to $17 \mathrm{~mA}$. While the injected current increases continuously to $20 \mathrm{~mA}$, the transverse modes are transited to $\mathrm{HE}_{10}$ or $\mathrm{EH}_{10}$. Higher modes like $\mathrm{HE}_{20}$ or $\mathrm{EH}_{20}$ modes happen when the injected current is higher to $29 \mathrm{~mA}$.
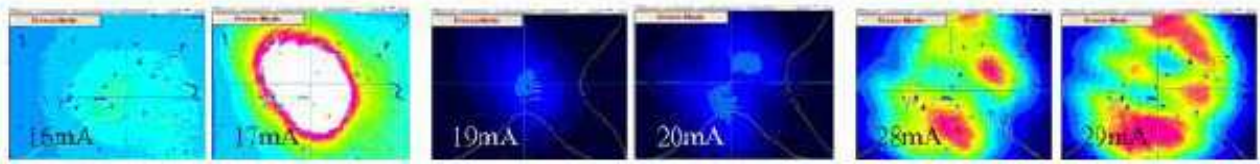

Fig. 18. The far-field pattern of $850 \mathrm{~nm}$ VCSEL as function of injected currents, oxidized times of $70 \mathrm{~min}$

Differently, $30^{\circ} \mathrm{C}$ laser beam profiles are shown in Fig. 19 after selectively oxidized times of $80 \mathrm{~min}$. From the profiles, it is very strange that the higher-order lasing modes like $\mathrm{HE}_{20}$ or $\mathrm{EH}_{20}$ modes occurs directly from spontaneous mode once the injected currents increase to $15 \mathrm{~mA}$. While the injected current increases continuously to $19 \mathrm{~mA}$, the transverse modes are transited to lower-order $\mathrm{HE}_{10}$ or $\mathrm{EH}_{10}$. Mode-merging phenomenon happen when the injected current is higher to $30 \mathrm{~mA}$
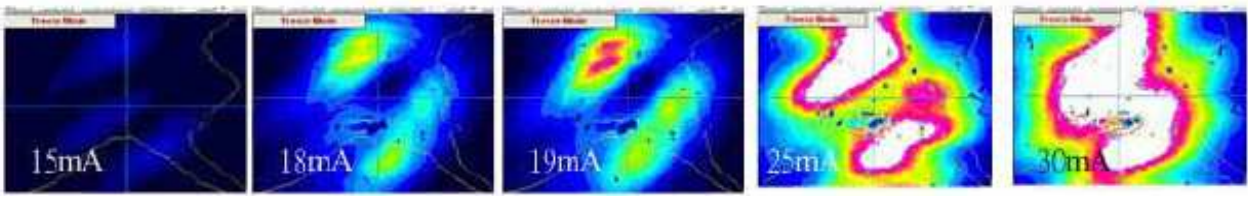

Fig. 19. The far-field pattern of $850 \mathrm{~nm}$ VCSEL as function of injected currents, oxidized times of $80 \mathrm{~min}$ 
Compared with the Fig. 17 and 19, the spontaneous mode is transited to lasing mode with respect to aperture size and injected current values. The main reason possibly is that the temperature increasing of the hetero-junction for VCSEL attribute to increasing injected current. This can result in the changes of refractive index in the cavity of VCSEL so that the $\mathrm{k}$ would be subsequently changed to be a large influence on the far-field mode-transition. The parameter of aperture size is also key factor for current density, which cause modetransition. The aperture size of oxidized times of $60 \mathrm{~min}$ for VCSEL is larger than one of oxidized times approaching to $80 \mathrm{~min}$. It may result in the divergent distribution and obscure profile for the mode patterns as displayed in the pattern transition increasing injected current from 23 to $24 \mathrm{~mA}$ shown in Fig. 17. In contrast with Fig. 19, the smaller aperture and threshold current density lead to constrictive mode patterns and clear profiles. Similarly, the formation of feature on mode-pattern transition has been explained as the mentioned before in Fig. 17 to 19. The asymmetric aperture window due to non-uniformity of selectively oxidized process may be lead to the initial laser mode appear with higher order mode. It also results in non-uniformity and asymmetry for pattern distribution.
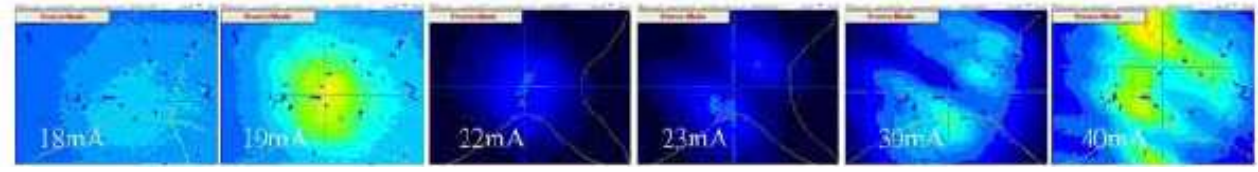

Fig. 20. The far-field pattern of $850 \mathrm{~nm}$ VCSEL as function of injected currents, oxidized times of $70 \mathrm{~min}$

Far-field patterns, $80{ }^{\circ} \mathrm{C}$ laser beam profiles are shown in Fig. 20 after selectively oxidized times of $70 \mathrm{~min}$. From this Figure, it shows that the $\mathrm{HE}_{00}$ lasing modes appear while injected

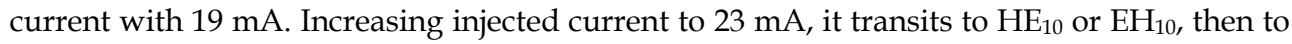
higher order mode of $\mathrm{HE}_{20}$ or $\mathrm{EH}_{20}$ while further increasing current to $40 \mathrm{~mA}$. In compared with Fig. 18 and 20, two mode pattern distributions are very similar excluding mode intensities. It can be to depict that insensitive operation temperature for far-field pattern distributions. The thermal effect like electron-phonon interaction mechanism leads to enhancement of non-radiation process which may be key factor for intensity degradation.

\subsection{Proton-Implant 850nm VCSEL (D. Burak. et.al., 1998),}

Contrast to the above selectively oxidized VCSEL performance, the best empirical and proton implanted parameters of device process are treated in the VCSEL sample. The temperature-dependent I-V measurements of the optimized proton-implanted VCSEL sample are shown in Fig. 21. Similarly, from 30 to $80^{\circ} \mathrm{C}$ of I-V measurement, the higher temperature is, the larger of slope of IV-curves are. (G. T. Dang et.al., 2003) The depicted phenomenon is previously mentioned. The differential resistances of the optimized VCSEL sample are shown in Fig. 22. From 30 to $80{ }^{\circ} \mathrm{C}$, the averagely differential resistance of proton-implanted $850 \mathrm{~nm}$ VCSEL are $36.8 \Omega$. The differential resistances and turn-on voltages of proton-implanted are higher than those of oxidized confined ones, respectively. It could be explained that the ion-implant process treated in the VCSEL causes some 


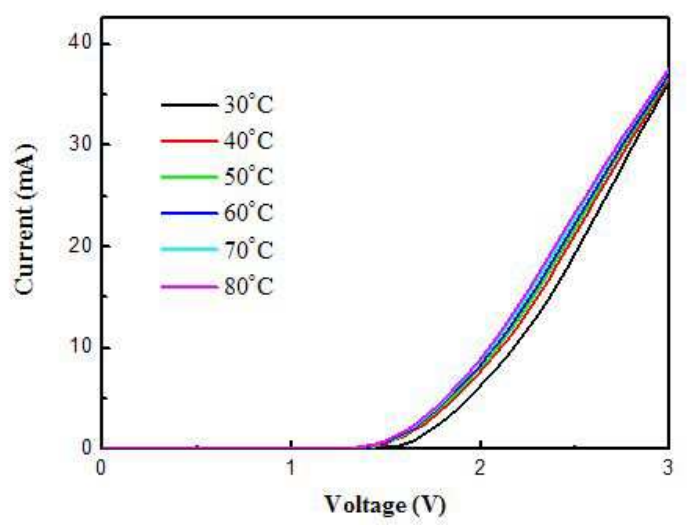

Fig. 21. I-V curve of proton-implant $850 \mathrm{~nm}$ VCSEL devices

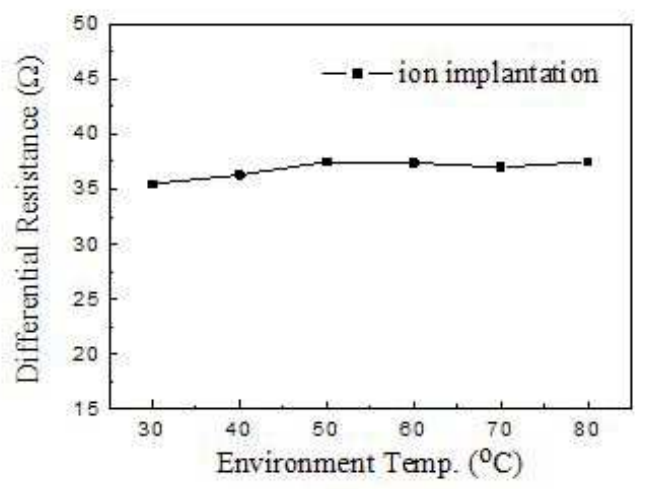

Fig. 22. The temperature-dependent differential resistance of proton-implant $850 \mathrm{~nm}$ VCSEL disorder and damage in contact region even though the high-resistance regions are designed to be fabricated far from the top contact layer. (E.W. Young et.al., 2003)

The temperature-dependent spectra of the optimistically ion-implanted VCSEL sample are shown in Fig. 23. From 30 to $80^{\circ} \mathrm{C}$ and under the driving current of $10 \mathrm{~mA}$. The shifts of FWHM and red-shifts of peak-wavelength are 0.12 and $0.07 \mathrm{~nm} /{ }^{\circ} \mathrm{C}$, respectively. It is worthy to note that the shifts of FWHM in the proton-implanted VCSEL is smaller with compared to that of above oxidized confined VESEL under the same effective dimension of the optical cavity. And the comparable red-shifts of peak-wavelength in the two different confined types. In the analysis on far-field patterns (Advantest Corp, 1993), $30^{\circ} \mathrm{C}$ laser beam profiles of the VCSEL sample after ion-implanted treatment are shown in Fig. 24. From the 


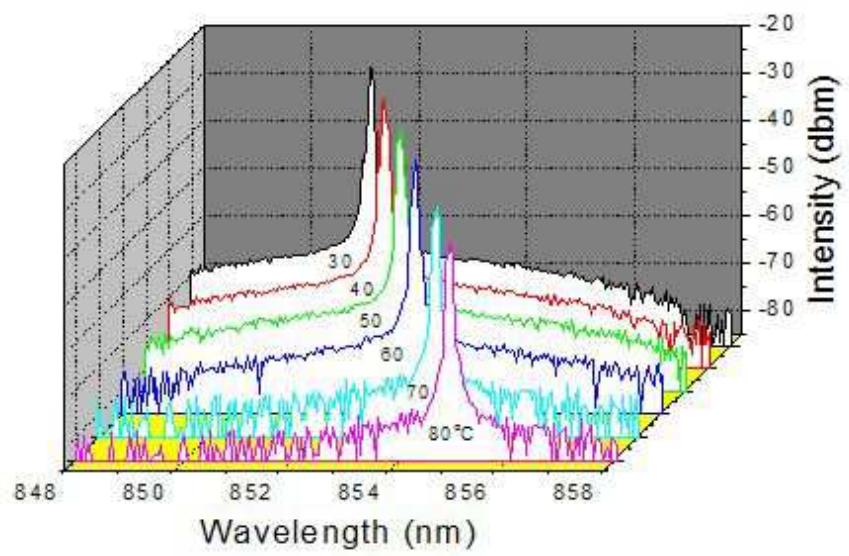

Fig. 23. The temperature-dependent spectra of Proton-Implant $850 \mathrm{~nm}$ VCSEL

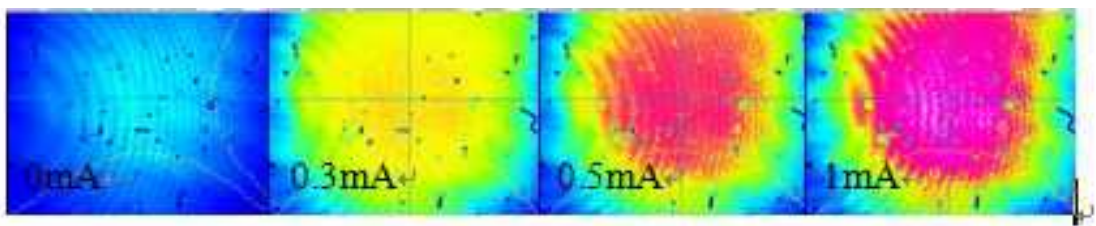

Fig. 24. The far-field pattern of Proton-Implant $850 \mathrm{~nm}$ as function of injected currents, temperature of $30^{\circ} \mathrm{C}$

diagram, it is clear to obtain that the single lasing modes occur suddenly from spontaneous mode once the injected currents increase to $0.3 \mathrm{~mA}$. While the injected current increases continuously to $1 \mathrm{~mA}$, lasing intensities eventually become stronger and the profile remain the same shape. The transverse modes always are single modes. And the threshold current of proton-implanted VCSEL is much smaller than that of the sample treated in oxidized confined process. (P. K. Kondratko et.al., 2003)

Similarly, $80^{\circ} \mathrm{C}$ laser beam profiles after ion-implanted treatment are shown in Fig. 25. From the profiles, it is found that the single fundamental lasing mode occurs suddenly from spontaneous mode once the injected currents increase to $1.2 \mathrm{~mA}$. And the profiles of far-field pattern remain the quasi-circular shape. While the injected current increases continuously to $1.3 \mathrm{~mA}$, the transverse modes still are single modes. Only lasing intensity becomes stronger like that of the low temperature operation. It can be depicted that the proton-implanted VCSEL have a good performance to be operated in higher circumambient temperature.

The experimental results in summary of the oxidized and proton-implanted confined VCSEL as sown in Table I, as well as the assistance of using theoretical DBR simulated with transfer matrix method (TMM), matrix calculating method (MCM), Marcatili's method. Table I demonstrates the superior performance of VCSEL treated in ion-implanted process 
contrast to the oxidized confined VCSEL. However, the low-differential resistance and lower-cost process with high-temperature oxidized treatment in VCSEL has some benefits for the specific optical-communication application as short-distance data transmission.

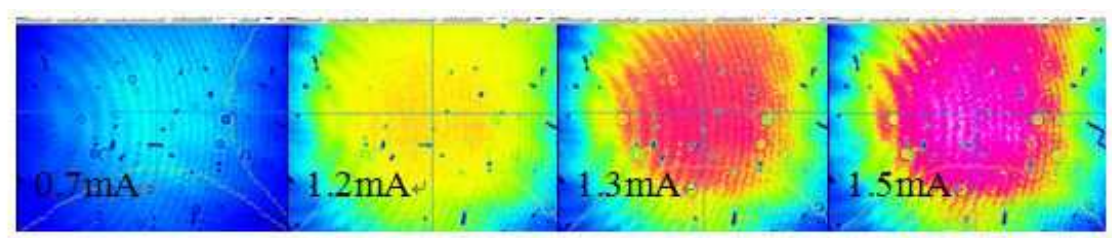

Fig. 25. the far-field pattern of Proton-Implant $850 \mathrm{~nm}$ as function of injected currents, temperature of $80^{\circ} \mathrm{C}$

\begin{tabular}{|c|c|c|c|c|}
\hline VCSEL & \multicolumn{2}{|c|}{ Oxidized } & \multicolumn{2}{c|}{ Ion Implanted } \\
\hline $\begin{array}{c}\text { Peak } \\
\text { wavelength }\end{array}$ & $859 \mathrm{~nm}$ & $\mathrm{IF}=30 \mathrm{~mA}$ & $851 \mathrm{~nm}$ & $\mathrm{IF}=10 \mathrm{~mA}$ \\
\hline $\begin{array}{c}\text { Threshold } \\
\text { current }\end{array}$ & $16.9 \mathrm{~mA}$ & $\mathrm{CW}$ & $3.2 \mathrm{~mA}$ & $\mathrm{CW}$ \\
\hline $\begin{array}{c}\text { Threshold } \\
\text { voltage }\end{array}$ & $1.9 \mathrm{~V}$ & $\mathrm{IF}=30 \mathrm{~mA}$ & $1.8 \mathrm{~V}$ & $\mathrm{IF}=10 \mathrm{~mA}$ \\
$\begin{array}{c}\text { Series } \\
\text { differential } \\
\text { Resistance }\end{array}$ & $25.8 \Omega$ & $\mathrm{IF}=30 \mathrm{~mA}$ & $36.8 \Omega$ & $\mathrm{IF}=10 \mathrm{~mA}$ \\
\hline Lasing mode & \multicolumn{2}{|c|}{ Multi mode } & Single mode \\
\hline
\end{tabular}

Table 1. The comparison sheets of oxide confined $850 \mathrm{~nm}$ VCSEL and Proton-Implant 850 nm VCSEL

\section{Conclusions}

In the theoretical simulation, the optical TMM and MCM method as well as multi-layer films evolution software of essential Macleod have been proposed to verify the model validity. Besides, the operation temperature leading changes of material refractive index is considered for reflectivity spectra on graded $\mathrm{Al}_{x} \mathrm{Ga}_{1-\mathrm{x}} \mathrm{As} / \mathrm{GaAs} \mathrm{DBR}$ mirrors. For oxidized confined $850 \mathrm{~nm}$ VCSEL, under injected current of $30 \mathrm{~mA}$ and the operation temperature increasing from 30 to $80^{\circ} \mathrm{C}$, the FWHM shifts and peak-wavelength red-shifts are $0.71 \pm 0.05$ and $0.06 \mathrm{~nm} /{ }^{\circ} \mathrm{C}$. It can be concluded that the aperture size, hetero junction temperature changes and uniformity of selectively oxidized process have very critical influences on the far-field mode pattern distributions, mode numbers, mode transitions. For protonimplanted $850 \mathrm{~nm}$ VCSEL, under smaller injected current of $10 \mathrm{~mA}$ and the operation 
temperature increasing in the same temperature region of the above oxidized confined VCSEL, the FWHM shifts and peak-wavelength red-shifts are 0.12 and $0.07 \mathrm{~nm} /{ }^{\circ} \mathrm{C}$, respectively. The summary of our experimental results as well as the assistance of the DBR simulation using the TMM, MCM and Macleod's models can be concluded that the optimized $850 \mathrm{~nm}$ VCSEL has been proposed in the promising application for high efficient and low-cost optical fiber and free space data communications in the future.

\section{References}

Talghader; J \& Smith, J. S. (1995). Thermal dependence of the refractive index of GaAs and AlAs measured using semiconductor multilayer optical cavities, Appl. Phys. Lett., vol. 66, pp. 335-337

Iga, K.; Ishikawa, S.; Ohkouchi, S. \& Nishimura, T. (1984). Room Temperature Pulsed Oscillation of GaAlAs/GaAs Surface-Emitting Injection Laser, Appl. Phys. Lett., vol. 45 , pp. $348-350$

Afromowitz M. A. (1974). Refractive Index of Ga1-xAlxAs, Solid State Communications, vol. 15 , pp. 59-63

C. Chen. (2002).Vertical-cavity surface-emitting laser with stable single transverse mode and stable polarization, SPIE .pp. 14-16, Taipei, Taiwan

Furman, Sh. \& Tikhonravov, A.V. (1992). Basics of optics of multilayer systems, pp. 21-26, ADAGP, Frontiers, France

S. Chuang. (1995). Physics of optoelectronic devices, pp. 242-278, John Wiley, New York

S. T. Su; S. F. Tang; T. C. Chen; C. D. Chiang; S. T. Yang \& W. K. Su. (2006). Temperature dependent VCSEL optical characteristics based on graded AlxGa1-xAs/GaAs distributed Bragg reflectors: reflectivity and beam profile analyses, SPIE. VerticalCavity Surface-Emitting Lasers X, Vol. 6132, pp. 0L01-0L10

Advantest Corp. (2002). R6243/44 DC voltage current source/monitor operation manual, chapter 3-4, Advantest Corp.,Tokyo, Japan,

Advantest Corp. (1994). Q8221 optical multi-power meter operation manual, chapter 4, Advantest Corp., Tokyo, Japan

Advantest Corp. (1993). Q8381A/8383 optical spectrum analyzer operation manual, chapter 4, Advantest Corp., Tokyo, Japan

D. Burak; S. A. Kemme; R. K. Kostuk \& R. Binder. (1998). Spectral identification of transverse lasing modes of multimode index-guided vertical-cavity surfaceemitting lasers, Appl. Phys. Lett., vol. 73, pp. 3501-3503,

G. T. Dang; R. Mehandru; B. Luo; F. Ren; W. S. Hobson; J. Lopata; M. Tayahi; S. N. G. Chu; S. J. Pearton; W. Chang \& H. Shen. (2003). Fabrication and Characteristics of High-Speed Implant-Confined Index-Guided Lateral-Current 850-nm Vertical Cavity Surface-Emitting Lasers, Journal of Lightwave Technology, vol. 21, NO. 4, APRIL

E. W. Young; Kent D. Choquette; Jean-François P. Seurin; Shun Lien Chuang; K. M. Geib \& Andrew A. Allerman. (2003). Comparison of Wavelength Splitting for Selectively Oxidized, Ion Implanted, and Hybrid Vertical-Cavity Surface-Emitting Lasers, IEEE Journal of Quantum Electronics, vol. 39, NO. 5, MAY 
P. K. Kondratko; E. W. Young; Jean-Fran; cois Seurin; Shun Lien Chuang \& K. D. Choquette. (2002). Performance of Proton-Implant/Oxide Aperture VCSELs and Comparison with Vector Optical Model, SPIE. Vertical-Cavity Surface-Emitting Lasers VI, vol. 4649, pp. $71-76$ 


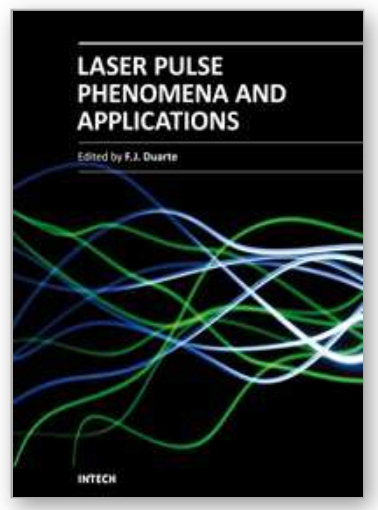

\section{Laser Pulse Phenomena and Applications}

Edited by Dr. F. J. Duarte

ISBN 978-953-307-405-4

Hard cover, 474 pages

Publisher InTech

Published online 30, November, 2010

Published in print edition November, 2010

Pulsed lasers are available in the gas, liquid, and the solid state. These lasers are also enormously versatile in their output characteristics yielding emission from very large energy pulses to very high peak-power pulses.

Pulsed lasers are equally versatile in their spectral characteristics. This volume includes an impressive array of current research on pulsed laser phenomena and applications. Laser Pulse Phenomena and Applications covers a wide range of topics from laser powered orbital launchers, and laser rocket engines, to laser-matter interactions, detector and sensor laser technology, laser ablation, and biological applications.

\section{How to reference}

In order to correctly reference this scholarly work, feel free to copy and paste the following:

Tzu-chiang Chen (2010). Numerical Simulations of Temperature-dependence on Distributed Bragg Reflector (DBR) and Performance Analyses for Proton-Implant/Oxide Confined VCSEL: Comparison with Transmission Matrix, Matrix Calculating Methods and Macleod Model, Laser Pulse Phenomena and Applications, Dr. F. J. Duarte (Ed.), ISBN: 978-953-307-405-4, InTech, Available from: http://www.intechopen.com/books/laser-pulsephenomena-and-applications/numerical-simulations-of-temperature-dependence-on-distributed-braggreflector-dbr-and-performance-a

\section{INTECH}

open science | open minds

\section{InTech Europe}

University Campus STeP Ri

Slavka Krautzeka 83/A

51000 Rijeka, Croatia

Phone: +385 (51) 770447

Fax: +385 (51) 686166

www.intechopen.com

\section{InTech China}

Unit 405, Office Block, Hotel Equatorial Shanghai

No.65, Yan An Road (West), Shanghai, 200040, China

中国上海市延安西路65号上海国际贵都大饭店办公楼405单元

Phone: +86-21-62489820

Fax: +86-21-62489821 
(C) 2010 The Author(s). Licensee IntechOpen. This chapter is distributed under the terms of the Creative Commons Attribution-NonCommercialShareAlike-3.0 License, which permits use, distribution and reproduction for non-commercial purposes, provided the original is properly cited and derivative works building on this content are distributed under the same license. 